\title{
Success and Safety of Cesarean Myomectomy in Women with Single Uterine Myoma
}

\author{
Nazdar Raouf* \\ Department of Obstetrics and Gynecology, Duhok Obstetrics and Gynecology Teaching Hospital, Iraq
}

Submission: February 24, 2021; Published: March 02, 2021

*Corresponding author: Nazdar Raouf, Department of Obstetrics and Gynecology, Duhok Obstetrics and Gynecology Teaching Hospital, Iraq

\begin{abstract}
Background: Cesarean myomectomy is the term used to describe the removal of fibroids at cesarean section ,most obstetricians are trained to avoid cesarean mymectomy. The aim for this study to determine the success and safety of the cesarean myomectomy and to evaluate the relationship between intra-operative and postoperative complications of the cesarean myomectomy in case of single uterine myomas.

Methods: This case-control study was conducted at the Duhok Obstetrics and Gynecology Teaching Hospital and Kurdistan Private Hospital in Iraqi Kurdistan between February 2016 and May 2019. The study included 61 pregnant women, they were divided into two groups ,Cesarean Myomectomy group and were compared with Cesarean Section group. Outcomes studied were duration of surgery, change in hemoglobin from pre-operative to post-operative period, need for blood transfusion, and duration of hospital stay, post-operative complications and follow up of patients up to 6 weeks postpartum.
\end{abstract}

Result: During the study period, twenty-one pregnant women successfully underwent cesarean myomectomy and were compared with the control group and included forty pregnant women not having fibroids who underwent cesarean section only. There were no significant differences among the patients in the both groups in terms of baseline characteristics and indications for cesarean section. Duration of surgery was highly significant increased in study group as compared to control group. No complications were noted in either group during this period nor maternal death was reported.

Conclusion: Myomectomy of a single myoma during cesarean section can be considered a safe and advantageous surgical procedure.

keywords: Cesarean Section; Myoma; Cesarean Myomectomy; Obstetrics and Gynecology

\section{Background}

Myomas, also known as fibroids, are benign tumors of the smooth muscle cells of the female reproductive organs [1]. Based on first-trimester ultrasound assessments, the prevalence of uterine fibroids during pregnancy ranges from $1.6 \%$ to $10.7 \%$ $[2,3]$. The effects of fibroid growth on pregnancy may start before conception and continue through the postpartum period, but however the majority of myomas do not increase in size and rarely lead to adverse outcomes during pregnancy [4-7].

Myomas during pregnancy are associated with a high risk of cesarean section(CS) [1]. One of the most controversial dilemmas among obstetricians is the removal of fibroids during cesarean delivery, a procedure referred to as cesarean myomectomy (CM) $[8,9]$. Textbooks suggest that $\mathrm{CM}$ is not recommended because of the high risk of hemorrhage associated with the procedure. Cesarean myomectomy patients may also require blood transfusion or cesarean hysterectomy, and they are at increased risk for postoperative morbidity. Even so, leaving the myomas in place is not entirely without complications $[10,11]$.

Several studies have demonstrated that CM can be performed safely, and the risk of anesthetic complications as well as the costs of multiple surgeries can be reduced $[12,13]$. The risks of hemorrhage and hysterectomy associated with CM maybe reduced by using techniques to minimize blood loss during the procedure $[7,14]$. therefore, this study aimed to explore the safety and success of CM outcome regarding intrapartum bleeding, relaparotomy, hysterectomy, sepsis, and maternal mortality. 


\section{Methods}

\section{Design and setting}

This case-control study was conducted at the Duhok Obstetrics and Gynecology Teaching Hospital and Kurdistan Private Hospital in Iraqi Kurdistan between February 2016 and May 2019. This study was approved This study was approved by the Institutional Review Board (IRB) of Kurdistan Board for medical specialist, and the protocols used in the study were approved by the Committee of Scientific research unit of Duhok Obstetrics and Genecology Teaching Hospital. The study included 61 pregnant women, they were divided into two groups; study group or (Cesarean Myomectomy group) included those who underwent CM and control group or (Cesarean Section group) included those who had undergone CS only.

The inclusion criteria were, pregnant women with documented myoma by antepartum ultrasound or by intra-operative findings, single myoma, and no other procedures at the time of cesarean section besides myomectomy should be done. Pregnant women with antepartum hemorrhage, coagulopathy, bleeding disorders, multiple gestation and any co- morbid conditions were excluded from the study. After complete history, clinical examination and investigations, written informed consent for surgery was taken in both the groups. In the study group consent for myomectomy was also taken and blood was arranged. Complications such as postpartum hemorrhage, blood transfusion, and cesarean hysterectomy were explained prior to the procedure. The operations were performed by surgeon experienced in the field of myomectomy operations and in managing cases of massive obstetric hemorrhage. Baseline characteristics of these patient were recorded, including maternal age, parity, gravidity, gestational age at delivery, neonatal body weight, and urgency of CS. indications for cesarean section as well as characteristics of myomas such as location, type, size, number, and histopathological analysis were also recoded.

Clinical outcomes examined were duration of surgery, change in hemoglobin level preoperatively to postoperatively, need for blood transfusion, duration of hospital stay, and complications including intra-operative bleeding, uterine atony, relaparotomy, vascular and organ injuries, cesarean hysterectomy, postpartum fever, sepsis, and maternal mortality. Intra-operative blood loss was collected into the surgical drape for operation and into the graduated bag of the aspirator cannula. The duration of surgery was calculated in minutes (calculated from skin incision to skin closure).

\section{Cesarean Myomectomy Technique}

In all cases, the abdominal incision was a low transverse incision, whereas the uterine incision to deliver the baby was a low transverse uterine incision. Following delivery of the baby, the third stage was actively managed. After the lower uterine segment incision was closed the uterine surface was evaluated for the types, locations, numbers and sizes of the myoma (Figure1).

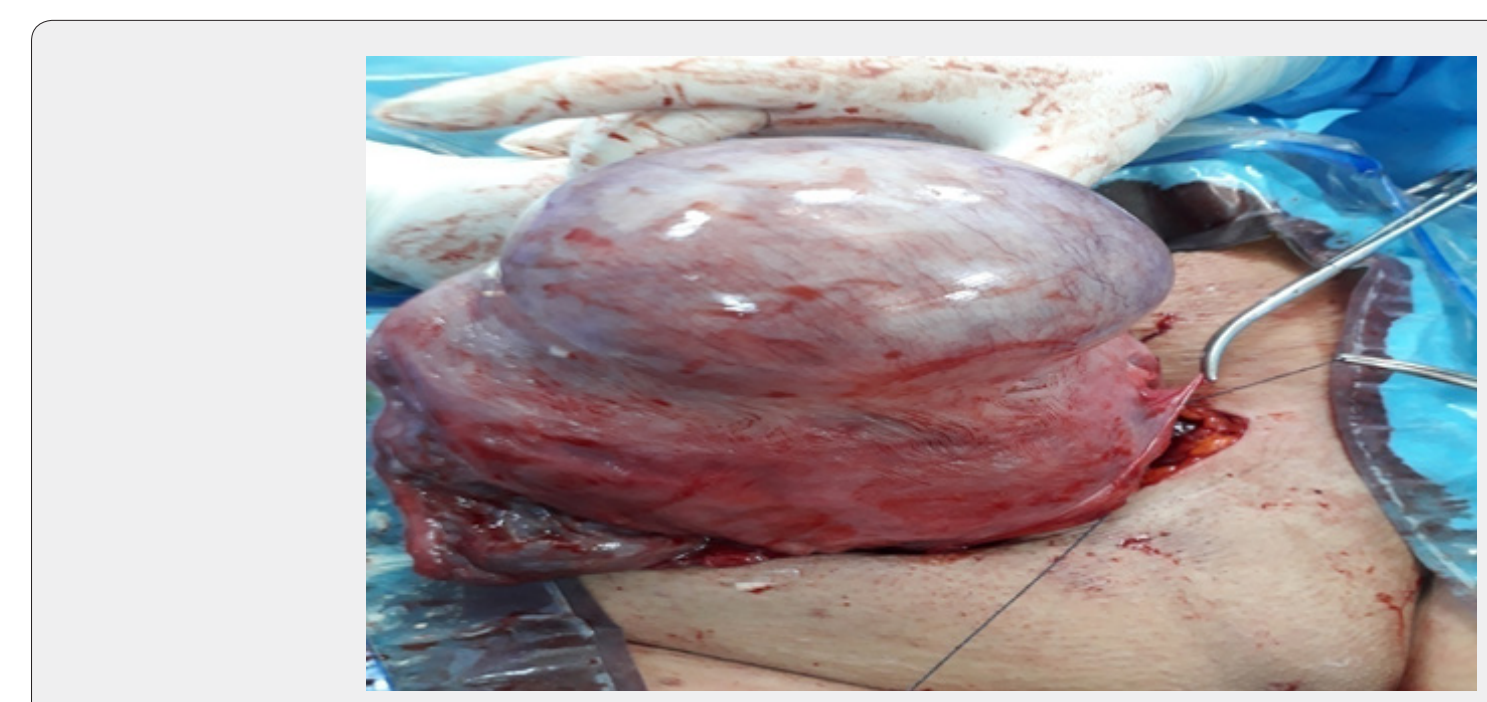

Figure 1: Large single myoma over the anterior surface of the uterus. Following delivery of the baby and placenta ,the lower uterine segment incision was closed then the uterine surface was evaluated for the types, locations, numbers and sizes of the myoma.

In cases of intramural myoma longitudinal incisions were made over the surface of the myoma by monopolar electrocoutery (Figure 2). After reaching the surface of myoma, edges were freed using sharp dissection then myoma was extract from its pseudo-capsule. Hemostasis was secured by a coagulation of the pseudo-capsule vessels .Sessile subserosal myoma were removed by making an elliptical incision over the myoma using electrocautery ,Pedunculated myoma were cut from the pedicle. When a myoma was located in the submucosa or in the posterior uterine wall, the endometrial myomectomy technique was used to make 


\section{Journal of Gynecology and Women's Health}

an endometrial incision over the submucosal myoma, the myoma was then enucleated. After a myoma mass was removed adequate approximation of the myometrium, myoma bed and all dead spaces were done using two layers of interrupted absorbable sutures (1-0 vicryl) then the serosa was sutured, using a continuous absorbable suture (2- 0 vicryl), as a third layer (Figure 3).

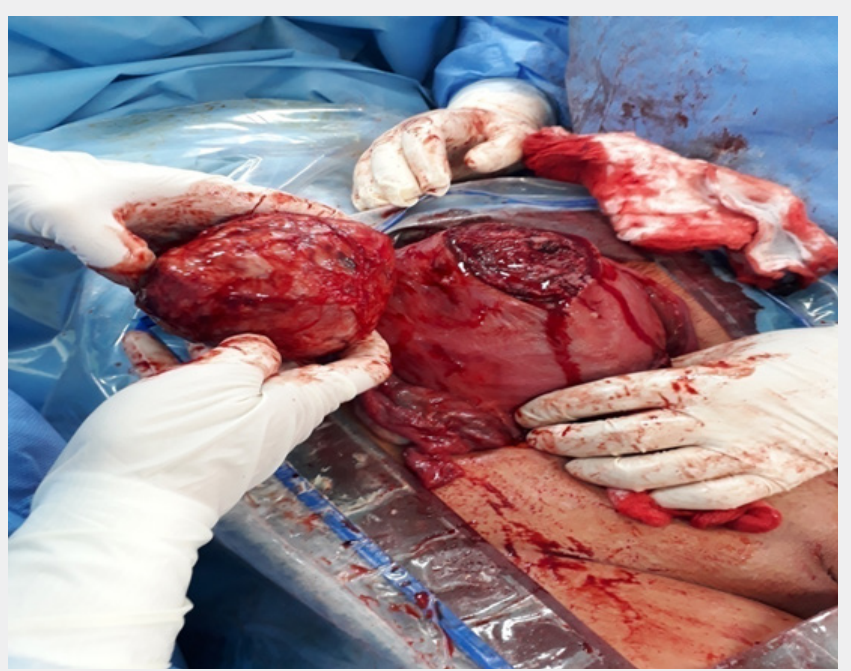

Figure 2: Uterus after removal of myoma mass during cesarean myomectomy. A longitudinal incisions were made over the surface of the myoma. After reaching the surface of myoma, edges were freed using sharp dissection then myoma was extracted.

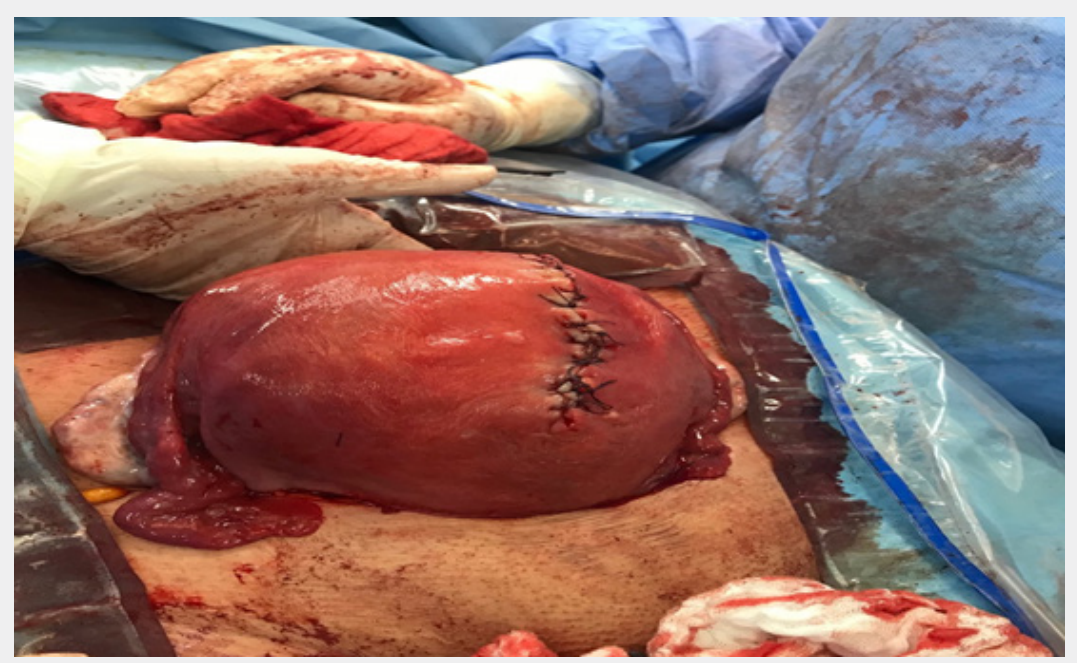

Figure 3: Uterus after suturing the myoma bed and serosa during cesarean myomectomy. Suturing of myoma bed and all dead spaces ,using two layers of interrupted absorbable sutures then the serosa was sutured, using a continuous absorbable suture, as a third layer.

Hemostasis was secured using standard technique of intracapsular myomectomy and oxytoxic agents such as oxytocin, misoprostol, and ergometrine (if not contraindicated) were used also, oxytocin infusion was continued for 4-8 hours postoperatively. All patients received a single dose of 1-gram Tranexamic acid in the form of an infusion over 20 minutes during the operation. All patients received intra-operative antibiotics intravenously $2 \mathrm{~g}$ of ampicillin or amoxicillin or $2 \mathrm{~g}$ cefazoline or ceftriaxone and 500mg metronidazole). Myoma specimens were sent for histopathological examination.

\section{Follow-up}

After surgery, all patients were cared for in high dependency units or similar areas. Their vital signs and temperatures were assessed, and they were monitored for vaginal blood loss and assessed for thromboprophylaxis. patients were discharged after 35 hours of operation in a good health. They attended follow-up examinations seven days and six weeks after the operation. Both groups were compared with respect to baseline characteristics, duration of surgery, change in hemoglobin from preoperative 
to post-operative period, need for blood transfusion, duration of hospital stay, post-operative complications and follow up of patients up to 6 weeks postpartum

\section{Statistical analysis}

The data were statistically analyzed using a software package, current versions IBM (SPSS) Statistic, descriptive statistics for nominal variables were expressed as number and percentage (\%), whereas quantitative variables were expressed as mean \pm standard deviation. Student's t-test was applied to difference of mean of quantitative variables. The chi-square distribution test was used to compare categorical data .For interpretation of results, $\mathrm{p}$ value $<0.05$ was considered significant.

\section{Result}

During the study period, from February 2016 to May 2019, twenty-one of pregnant women had undergone CM were compared with the control group and included forty pregnant women not having fibroids who underwent CS only.

\section{Baseline characteristics of patients}

Table 1: Baseline characteristics of patients selected for cesarean myomectomy.

\begin{tabular}{|c|c|c|c|}
\hline Patient Characteristics & Cesarean Myomectomy Group (N=21) & Cesarean Section Group (N=40) & P-Value \\
\hline Maternal age (years) & $33.11 \pm 8.21$ & $35.31 \pm 3.23$ & 0.139 \\
\hline Gravidity & $1.44 \pm 0.53$ & $1.52 \pm 1.04$ & 0.742 \\
\hline Parity & $1.31 \pm 0.33$ & $1.35 \pm 0.42$ & 0.706 \\
\hline Gestational age (weeks) & $38.01 \pm 1.05$ & $38.4 \pm 1.21$ & 0.216 \\
\hline Neonatal body weight & $3132.02 \pm 323.57$ & $3264.11 \pm 326.34$ & 0.137 \\
\hline Elective CS & $19(31.14 \%)$ & $31(50.81 \%)$ & 0.144 \\
\hline Emergency CS & $2(3.27 \%)$ & $9(14.75 \%)$ & 0.173 \\
\hline
\end{tabular}

Quantitative variables presented as mean $\pm \mathrm{SD}$, nominal variables as number (percent), $\mathrm{P}<0.05=$ Significant, $\mathrm{P}<0.001=$ highly significant, $\mathrm{P}>$ $0.05=$ Not significant

The baseline characteristics of these patients are summarized in Table 1. Twenty-one myomas were removed in 19 elective and 2 emergency cesarean section in study group while, 31 elective and 9 emergency cesarean section done in control group. All patients received spinal anesthesia for the operation. There were no significant differences among the patients in both groups in terms of baseline characteristics such as age, gravidity, parity, gestational age at delivery, neonatal body weight, and urgency of CS.

\section{Indications for cesarean section}

Indications for cesarean section in both groups are summarized in Table 2. When cesarean indications were considered a noncephalic presentation was the first among all indications, followed by previous scar. The groups were similar in terms of indications for cesarean section.

Table 2: Indications for caesarean section.

\begin{tabular}{|c|c|c|c|}
\hline Indications & Cesarean Myomectomy Group $(\mathrm{N}=21)$ & Cesarean Section Group $(\mathrm{N}=40)$ & P-Value \\
\hline Non-cephalic presentation & $7(11.47 \%)$ & $15(24.59 \%)$ & 0.228 \\
\hline Previous scar & $4(6.55 \%)$ & $12(19.67 \%)$ & 0.178 \\
\hline Infertility & $3(4.91 \%)$ & $5(8.19 \%)$ & 0.637 \\
\hline Maternal request & $3(4.91 \%)$ & $4(6.55 \%)$ & 0.799 \\
\hline Bad obstetric history & $2(3.27 \%)$ & $1(1.63 \%)$ & 0.68 \\
\hline Prolonged labor & $1(1.63 \%)$ & $2(3.27 \%)$ & 0.709 \\
\hline Fetal distress & $1(1.63 \%)$ & $1(1.63 \%)$ & 1 \\
\hline
\end{tabular}

Data are presented as number (percent), $P>0.05=$ Not significant, $P<0.05=$ Significant

\section{Myoma characteristics}

Myoma characteristics are summarized in Table 3. In ten cases $(47.62 \%)$, the myoma was located at the anterior wall. In seven cases $(33.33 \%)$, it was fundal. In two cases $(9.52 \%)$, the myoma was located in the lower uterine segment. In two cases $(9.52 \%)$, the myoma was located at the posterior wall. The myoma was subserosal in nine cases (42.86\%), intramural in 10(47.62\%), and submucosal in two (9.52\%).Myomas were5-7 $\mathrm{cm}$ in size in eight cases (38.10\%) cases and $8-14 \mathrm{~cm}$ in 13 (61.90\%). All cases involved a single myoma. All specimens were sent for histopathology, and all revealed benign myomas. 
Table 3: Myomas characteristics.

\begin{tabular}{|c|c|}
\hline Myomas Characteristics & Values \\
\hline Location & All myomas \\
\hline Anterior wall & $10(47.62 \%)$ \\
\hline Fundus & $7(33.33 \%)$ \\
\hline Lower uterine segment & $2(9.52 \%)$ \\
\hline Posterior wall & $2(9.52 \%)$ \\
\hline Type & All myomas \\
\hline Subserosal & $9(42.86 \%)$ \\
\hline Intramural & $10(47.62 \%)$ \\
\hline Submucosa & $2(9.52 \%)$ \\
\hline Size & All myomas \\
\hline $5-7 \mathrm{~cm}$ & $8(38.10 \%)$ \\
\hline $8-14 \mathrm{~cm}$ & $13(61.90 \%)$ \\
\hline
\end{tabular}

\begin{tabular}{|c|c|}
\hline Number & All single \\
\hline Histopathology report & All benign \\
\hline
\end{tabular}

Data are presented as number (percent)

\section{Surgical consequences}

The surgical consequences and outcomes of cesarean CM compared with CS group are summarized in Table 4. The mean operative time was longer for cesarean myomectomy group $(48.61 \pm 3.23)$ as compared to cesarean section group $(20.22 \pm 2.11)$ and this difference was statistically highly significant $(\mathrm{P}<0.001)$. The mean amount of blood loss in the intra-operative period in CM group was $440 \pm 60$, while in CS group was $390 \pm 20$, this difference was not statistically significant. The difference between $\mathrm{CM}$ and $\mathrm{CS}$ group with respect to pre-operative and post-operative hemoglobin mean value was statistically insignificant. The mean duration of hospital stay in CM group was $33 \pm 21.22$ while in CS group was $30 \pm 11.13$. This difference was statistically insignificant

Table 4: Surgical consequences of cesarean myomectomy group compared with cesarean section group.

\begin{tabular}{|c|c|c|c|}
\hline Parameters & $\begin{array}{l}\text { Cesarean Myomectomy Group } \\
\qquad(\mathrm{N}=21)\end{array}$ & $\begin{array}{l}\text { Cesarean Section Group } \\
\qquad(\mathrm{N}=40)\end{array}$ & P-Values \\
\hline Surgical time(minutes) & $48.61 \pm 3.23$ & $20.22 \pm 2.11$ & $<0.001$ \\
\hline Amount of blood loss $\left(\mathrm{ml}^{*}\right)$ & $400 \pm 30$ & $390 \pm 20$ & 0.125 \\
\hline Pre-operative Hb\# level (g/dl§) & $11.51 \pm 0.72$ & $11.22 \pm 1.62$ & 0.439 \\
\hline Post-perative Hb\# level (g/dl§) & $10.52 \pm 1.12$ & $10.42 \pm 1.23$ & 0.757 \\
\hline Hospital stay (hours) & $33 \pm 21.22$ & $30 \pm 11.13$ & 0.47 \\
\hline
\end{tabular}

${ }^{*} \mathrm{ml}=$ milliliter, ${ }^{\mathrm{s}} \mathrm{g} / \mathrm{dl}=$ gram /deciliter, ${ }^{*} \mathrm{Hb}=$ Hemoglobin

Data are presented as mean $\pm S D$ (percent), $P<0.05=$ Significant, $P<0.001$ =highly significant, $P>0.05=$ Not significant

None of the patients had fevers in the postoperative period, and none required a blood transfusion or cesarean hysterectomy. None of the patients experienced atony and postpartum hemorrhage. No relaparotomy and organ injury or vascular complications developed in either group. Neither sepsis nor maternal death was reported in either group. Patients in both groups were followed up to 6 weeks postpartum. No complications were noted in either group during this period. Twenty-one pregnant women successfully underwent cesarean myomectomy.

\section{Discussion}

There is no consensus among obstetricians regarding the performance of CM nevertheless, Recent studies have shown that CM can be performed safely and successfully by an experienced obstetrician in carefully selected patients, particularly when it involves a single myoma, as well as when they are subserous and pedunculated myomas, although there are many studies in literature that investigate $\mathrm{CM}$, those evaluating single myomectomy are rare [15-17].

Our data indicate that there was no difference between CM group and CS group, in term of baseline characteristics, indications for cesarean section, pre- and post-operative hemoglobin values, and complications related to $\mathrm{CM}$. The only parameter that affects CM group was the duration of operation. A retrospective study evaluated study group underwent CM and control group with documented fibroids who underwent CS alone, the two groups were similar with respect to median age, median parity and median gestational age [18]. A retrospective case control study, the study group included 15 term pregnant women who had undergone $\mathrm{CM}$ and control group included 15 women who had undergone CS only and not having myoma, difference in age was reported that his could be due to increased incidence of fibroids with increasing age [19].

In recent decades, some studies have demonstrated that $\mathrm{CM}$ did not increase risk of uterine atony and intra-operative hemorrhage compared to CS without myomectomy [20]. In the present study, no cases were complicated by uterine atony or intra-operative bleeding. In a retrospective study involving 111 women with $\mathrm{CM}$ and 257 women undergoing CS alone noted no significant difference in incidence of intra-operative hemorrhage [18]. In 1989, Burton et al were probably the first to report the procedure of a myomectomy during pregnancy and CS. Thirteen 
other women had incidental myomectomy at CS; one of these had an intra-operative hemorrhage [21]. On the other hand, one study reported nine cases of CM three had severe hemorrhage needing hysterectomy [2]. some authors have reported high morbidity especially hemorrhage [10]. Relaparotomy reported in one study resulted in hysterectomy and maternal death due to massive hemorrhage [22]. In another study, CM was performed on 25 patients, and no patient required cesarean hysterectomy [23]. In the present study, no cases of relaparotomy, cesarean hysterectomy or maternal death were reported.

Several methods have been used to minimize bleeding during $\mathrm{CM}$, such as high-dose oxytocin, devascularization, uterine tourniquet, electrocoutery, and several surgical techniques $[18,24-27]$. In one study the authors used an intra-capsular myomectomy technique [28]. While in another study the author used the purse-string suture technique [29]. One study reported that experience of the surgeon also should be considered [30]. In our study both intra-capsular myomectomy and electrocautery were used, also we administered a uterotonic agents such as oxytocin intraoperatively and postoperatively for all patients as well as misoprostol and ergometrine.

During CM both location and size of myomas should be considered, in one study reported that myomas located in the lower segment should be removed [18]. Many authors reported that removal of large or intramural myomas should be avoided during CS [31]. While others reported removal of huge myoma during CS $[32,33]$. Another study reported that only peduncular myomas and small size myomas of less than $6 \mathrm{~cm}$ should be removed [34]. In one study reported that the myoma diameter was found to be larger in the group with complications [35]. Two studies suggested that CM should be avoided in intramural myomas within fundus and myoma located in cornua of uterus as both sites are associated with complications $[18,36]$. In our study, all cases were single uterine myoma. The largest myoma size removed was $15 \mathrm{~cm}$ and the smallest was $5 \mathrm{~cm}$, also in this study (intramural, submucosal, subserosal, fundal, lower uterine segment and anterior as well as posterior wall myomas) all were removed, no case of myoma located in cornua of uterus was reported.

In our study, CM was not associated with obvious changes in hemoglobin levels, blood transfusion was not required. A meta-analysis was conducted including nine studies, 44women underwent CM and 639 underwent CS alone. All of them found no significant difference in change in hemoglobin levels from pre-operative to post-operative period [31]. A comparative study of CM with abdominal myomectomy on 33 women of similar characteristics in each group was done. Blood loss and change in hemoglobin between two groups were not statistically significant and no complication was encountered [37]. In one study comparing 47 pregnant women having fibroids undergoing CM with 94 pregnant women having myoma undergoing CS alone, the difference between preoperative and post-operative hemoglobin

\section{was significant [36].}

In present study the duration of surgery in study group was longer in compared to control group. This difference was statistically highly significant. Kwawukume and Hassiakos et al showed significant difference in duration of operation between the two groups in their study $[24,36]$. Roman and Tabsh reported no significant difference in duration of surgery between study and control groups [18]. Meta-analysis conducted by Song D showed operative time to be 4.94 minutes longer in CM group, but again the difference was not significant [31]. In another study which evaluated 165 patients, myomectomy was carried out in 65 patients; operating times were longer in the myomectomy group, but there was no increase in postoperative complications compared to the group which did not undergo myomectomy [14].

There was no difference in duration of hospital stay and postoperative complications in present study as well as in other studies $[18,31,36,38]$. Present study and most other studies in literature show that the only significant difference between study and control group was duration of surgery which was significantly more in study group. Most of the studies included pregnant patients with myoma undergoing CS alone as control group and compared them with CM as study group. However, in our study pregnant women not having myoma underwent CS were taken as controls and compared with pregnant women with myoma underwent CM as study group.

\section{Strengths and limitations}

This study had two limitations that must be considered. First, the sample size was insufficient. Second, we had no information regarding the long-term outcomes of $\mathrm{CM}$. The major strengths of our study are that all patients had only a single myoma of a wide range of sizes and that the surgeries were performed by experience surgeon trained in surgical treatment of obstetric hemorrhage and CM.

\section{Conclusion}

Myomectomy of a single myoma during CS can be considered a safe surgical procedure, regardless of the size without affecting adversely the intra-operative and postoperative course however, it should be performed by an obstetrician with experience in managing cases of massive obstetric hemorrhage. The operation decision should be considered on case-to-case basis with the facility of blood banks, expert anesthetist, intensive care units. All risks associated with the procedure should be carefully discussed with the patients. Hence, our results could be useful to obstetricians who choose to perform $\mathrm{CM}$; it is advantageous for the patient because it avoids second operation, anesthesia complications, and it is cost saving. Further studies involving a large sample size and various myoma types are warranted, also long-term outcomes and the method of delivery in subsequent pregnancies should be considered. 


\section{Acknowledgment}

We would like to thank the operation and laboratory staff, anesthetist's team and postgraduate students involved in the trial for their hard work, including everyone involved in the collection and interpretation of the data. We would also like to thank Editage (www.editage.com) for their English language editing service.

\section{Ethics approval and consent to participate}

The ethical approval from the local ethics and scientific committee was obtained. The written informed consent of all the participants was obtained.

\section{References}

1. Sparic R (2014) Uterine myomas in pregnancy, childbirth and the puerperium. Srp Arh Celok Lek 142(1-2): 118-124.

2. Exacoust C, Rosati P (1993) Ultrasound diagnosis of uterine myomas and complications in pregnancy. Obstet Gynecol 82(1): 97-101.

3. Laughlin SK, Baird DD, Savitz DA, Herring AH, Hartmann KE, et al. (2009) Prevalence of uterine leiomyomas in the first trimester of pregnancy: an ultrasound-screening study. Obstet Gynecol 113(3): 630-635.

4. Muram D, Gillieson M, Walters JH (1980) Myomas of the uterus in pregnancy: ultrasonographic follow-up. Am J Obstet Gynecol 138(1): 16-19.

5. Rosati P, Exacoustos C, Mancuso S (1992) Longitudinal evaluation of uterine myoma growth during pregnancy. A sonographic study. J Ultrasound Med 11(10): 511-515.

6. Vergani P, Ghidini A, Strobelt N, Roncaglia N, Locatelli A, et al. (1994) Do uterine leiomyomas influence pregnancy outcome? Am J Perinatol 11(5): $356-358$

7. Qidwai GI, Caughey AB, Jacoby AF (2006) Obstetric outcomes in women with sonographically identified uterine leiomyomata. Obstet Gynecol 107: 376-382.

8. Park BJ, Kim YW (2009) Safety of cesarean myomectomy. Obstet Gynaecol Res 35(5): 906-911.

9. Sparic R, Nejkovic L, Mutavdzic D, Malvasi A, Tinelli A, et al. (2014) Conservative surgical treatment of fibroids. Acta Chir Iugosl 61: 11-66.

10. Davis JL, Ray-Mazumder S, Hobel CJ, Baley KA, Sassoon DE, et al. (1990) Uterine leiomyomas in pregnancy: a prospective study. Obstet Gynecol 75(1): 41-44.

11. Kwawkume EY (2002) Myomectomy during cesarean section. Int J of Gynecol Obstet 76(2): 183-184.

12. Awoleke JO (2013) Myomectomy during caesarean birth in fibroidendemic, low-resource settings. Obstet Gynecol Int p. 520834.

13. Febo G, Tessarolo M, Leo L, Arduino S, Wierdis T, et al. (1997) Surgical management of leiomyomata in pregnancy. Clin Exp Obstet Gynecol 24(2): 76-78.

14. Cunningham FG, Gant NF, Levenok KJ, Gilstrap LC, Hauth JC, et al. (2001) Abnormalities of the reproductive tract. In: Williams Obstetrics, In: (21 $1^{\text {st }}$ edn.), McGraw Hill, New York, USA, p. 930.

15. Sparic R, Malvasi A, Kadija S, Babović I, Nejković L, et al. (2017) Tinelli A Cesarean myomectomy trends and controversies: an appraisal. J Matern Fetal Neonatal Med 30: 1114-1123.

16. Malvasi A, Stark M, Tinelli A (2015) Cesarean myomectomy. In: Tinelli
A, Malvasi A (Eds.), Uterine myoma, myomectomy and minimally invasive treatments. In: (1 $1^{\text {st }}$ edn.), Springer, Berlin, pp. 237-252.

17. Segars JH, Parrott EC, Nagel JD, Xiaoxiao CG, Xiaohua G, et al. (2014) Proceedings from the third national institutes of health international congress on advances in uterine leiomyoma research: comprehensive review, conference summary and future recommendations. Hum Reprod Update 20(3): 309-333.

18. Roman AS, Tabsh KM (2004) Myomectomy at time of cesarean delivery: a retrospective cohort study. BMC Pregnancy Childbirth 4(1): 14-17.

19. Jaiswar SP, Srivastava P, Priyadarshini A, Deo S, Shankhwar P, et al. (2015) Safety of cesarean myomectomy with huge myoma compared with uncomplicated cesarean section in Indian scenario. Int J Reprod Contracept Obstet Gynecol 4:1696-1699.

20. Kwon DH, Song JE, Yoon KR, Lee YK (2014) The safety of cesarean myomectomy in women with large myomas. Obstet Gynecol Sci 57(5): 367-372.

21. Burton CA, Grimes DA, March CM (1989) Surgical management of leiomyomata during pregnancy. Obstet Gynecol 74(5): 707-709.

22. Seffah JD (2005) Relaparotomy after cesarean section. Int J Gynecol Obstet 88: 253-257.

23. Ehigiegba AE, Ande AB, Ojobo SI (2001) Myomectomy during cesarean section. Int J Gynecol Obstet 75(1): 21-25.

24. Kwawukume EY (2002) Caesareanmyom ectomy. Afr J Reprod Health 6(3): 38-43.

25. Sapmaz E, Celi H, Altungul A (2003) Bilateral ascending uterine artery ligation vs. tourniquet use for hemostasis in cesarean myomectomy: a comparison. J Reprod Med 48(12): 950-954.

26. Incebiyik A, Hilali NG, Camuzcuoglu A, Vural M, Camuzcuoglu H, et al. (2014) Myomectomy during caesarean: a retrospective evaluation of 16 cases. Arch Gynecol Obstet 289(3): 569-573.

27. Desai BR, Patted SS, Pujar YV, Sherigar BY, Das SR, et al. (2010) A novel technique of selective uterine devascularization before myomectomy at the time of cesarean section: a pilot study. Fertil Steril 94(1): 362364.

28. Tinelli A, Malvasi A, Mynbaev OA (2014) The surgical outcome of intracapsular cesarean myomectomy. A match control study. J Matern Fetal Neonatal Med 27(1): 66-71.

29. Lee J H, Cho DH (2011) Myomectomy using purse-string suture during cesarean section. Arch Gynecol Obstet 283(Suppl 1): 35-37.

30. Vitale SG, Padula F, Gulino FA (2015) Management of uterine fibroids in pregnancy: recent trends. Curr Opin Obstet Gynecol 27(6): 432-437.

31. Song D, Zhang W, Chames MC (2013) Myomectomy during cesarean delivery. Int J Gynaecol Obstet 121: 208-213.

32. Leanza V, Fichera S, Leanza G (2011) Huge fibroid (g. 3.000) removed during cesarean section with uterus preservation: a case report. Ann Ital Chir 82(1): 75-77.

33. Ma PC, Juan YC, Wang ID (2010) A huge leiomyoma subjected to a myomectomy during a cesarean section. Taiwan J Obstet Gynecol 49(2): 220-222.

34. Awoleke JO (2013) Myomectomy during caesarean birth in fibroidendemic, low-resource settings. Obstet Gynecol Int, p. 520834.

35. Kim YS, Choi SD, Bae DH (2010) Risk factors for complications in patients undergoing myomectomy at the time of cesarean section. J Obstet Gynaecol Res 36(3): 550-554. 
36. Hassiakos D, Christopoulos P, Vitoratos N, Xarchoulakou E, Vaggos G, et al. (2006) Myomectomy during cesarean section: a safe procedure? Ann New York Acad Sci 1092(1): 408-413.

37. Mangala JK, Sreedhar S, Sumathy S, Rajammal B (2016) Retrospective study of 53 cases of caesarean myomectomy regarding its safety and feasibility. Int J Reprod Contracept Obstet Gynecol 5(4): 1158-1161.
38. Topcu HO, Iskender CT, Timur H , Kaymak O, Memur T, et al. (2015) Outcomes after cesarean myomectomy versus cesarean alone among pregnant patients with uterine leiomyomas. Int J Gynecol Obstet. Int J Gynaecol Obstet 130(3): 244-246.
This work is licensed under Creative Commons Attribution 4.0 License DOI: 10.19080/JGWH.2021.21.556054

\section{Your next submission with Juniper Publishers will reach you the below assets}

- Quality Editorial service

- Swift Peer Review

- Reprints availability

- E-prints Service

- Manuscript Podcast for convenient understanding

- Global attainment for your research

- Manuscript accessibility in different formats

( Pdf, E-pub, Full Tsext, Audio)

- Unceasing customer service

Track the below URL for one-step submission https://juniperpublishers.com/online-submission.php 